Session 2353

\title{
Teaching Failure Analysis as an Independent Design Experience
}

\author{
David V. Niebuhr \\ California Polytechnic State University, San Luis Obispo, CA 93407
}

\begin{abstract}
Failure analysis of an engineering component is similar to building a puzzle with only some of the pieces. The engineer is left to interpret the data and make an educated conclusion. Undergraduate engineers, while enjoying the investigative experience, are somewhat intimidated by the many unknowns. In this course students select a failed engineering component and investigate the source of its demise. The evolution of the failure analysis course over 5 years is described, as well as, changes in expectations and deliverables dramatically increased the quality of work. It was found that by fostering peer review of progress during the quarter and introducing numerous case studies that student performance increased while anxiety decreased. A design component is introduced through the student's development of the analysis process and by requiring specific actions to prevent future failures.
\end{abstract}

\section{Introduction}

Design as an engineering experience has become a prominent topic in recent years. At the 2004 ASEE annual conference more than 100 presentations were given that discussed some aspect of design for a complete engineering education. The importance of design in engineering curriculum is well documented and supported by Department of Education data. ${ }^{1}$ Design is commonly thought of as the creation of a widget, such as a speaker system or an airplane engine, using certain design constraints. However, design can also encompass a process to achieve a desirable end result. Process engineering is widely utilized in manufacturing and chemical engineering. ${ }^{2,3}$ In many instances designing how to make something is more challenging than the original design of the component. For example, in the pharmaceutical industry attaining stability in synthesized molecules is an immense challenge. ${ }^{4}$ A more common example, in manufacturing, is how to make a machine component economically, since in most cases several processes are possible (machining, casting, etc.). Manufacturing education commits numerous resources to ensure students are well versed in process design., 6

Failure analysis, as the name suggests, is the technique of determining the root cause for a failure. The failure may be as mundane as a broken tool or as catastrophic as a passenger airline crash. The process of failure analysis is much like detective work in that a large number of interrelated factors must be understood and in some cases very little evidence is present. 
Regardless of the type of failure an established method of approach has been established. Below is a summary of steps taken in the process of a failed metallic engineering component. ${ }^{7}$

1. Collection of Background data

2. Preliminary Evaluation of the Failed Part

3. Non-destructive testing

4. Selection of representative specimens from failure

5. Macro and microscopic examination

6. Mechanical testing

7. Chemical analysis

8. Testing under simulated service condition

9. Formulation of probable conclusion

The design aspect of failure analysis is in how the above steps are executed. Different failures require different analytical tools and/or investigative techniques. Additionally, the amount of time and energy (translating to money) spent on determining the cause of failure must also be established. In determining the course of action there is no substitute for experience and exposure to a myriad of failure case studies.

The undergraduate failure analysis course is a senior level class taught predominantly to materials engineers. The objective of the course is to analyze a failed engineering component and determine the source of its demise. The components are typically metallic but on occasion a polymer, ceramic or composite material may be investigated. Analysis of non-metallic components is more difficult as the department lacks the analytical tools used for characterization. Depending on the part chosen (and approved by the instructor) the failure mode may be simple (fatigue of a spring) or complex (fracture of a lower control arm of a BMW). The students are given constraints (time, cost, availability of analytical techniques, etc.) and are then "turned loose." The structure of the course is described followed by a discussion of how the design component was integrated and the result of its inclusion.

\section{Course Description}

The basic model of thoroughly investigating a single component has been very successful in focusing the students on an engineering challenge that may not have an apparent solution. Additionally, it promoted project management to ensure timely completion. The outline of the course in winter 2000 is presented as a baseline followed by the most current offering in winter 2004. (There is no final description as the course in under constant revision and improvement). The course is currently being taught utilizing the design methods established in 2004. In terms of grading $50 \%$ of the points earned come from the final written report and oral presentation given to the class. The other $50 \%$ come from short quizzes, a lab notebook and failure analysis activities.

\section{Winter 2000}

The course ran 10 weeks and included two three hour lab periods and one 50 minute lecture. The course had a prerequisite of Materials Inspection which gave students an introduction to 
non- destructive testing methods including radiography, ultrasonic, dye penetrant, magnetic particle and eddy current. Materials Inspection was a good introduction to inspecting metals and characterizing components that may or may not have failed. The failure analysis course began with a brief overview of NDT and then followed the topics as summarized in Table 1.

\begin{tabular}{|c|c|c|}
\hline Week & Lecture Topic & Lab Activity \\
\hline \hline 1 & Introduction / Failure & Lab Safety / Introduction \\
\hline 2 & Review of NDT & Independent Work \\
\hline 3 & Review of NDT & Independent Work \\
\hline 4 & Fracture Modes & Independent Work \\
\hline 5 & Fracture Modes & Independent Work \\
\hline 6 & Fatigue & Independent Work \\
\hline 7 & Fatigue & Independent Work \\
\hline 8 & Corrosion Failures & Independent Work / Presentations \\
\hline 9 & Wear Failures & Presentations \\
\hline 10 & Specific case studies & \\
\hline
\end{tabular}

Table 1. Winter 2000 Failure Analysis Course Outline

The course was taught as a two laboratory / one lecture mode, which gave ample time for students to complete their projects but lacked sufficient time for lecture on advanced topics. The first week in lecture and lab introduced students to the expectations and deliverables for the quarter. Beyond that the labs were loosely structured with students working in parallel to each other, with the instructor available for consultation. The lecture topics covered included:

- NDT, non-destructive testing. This review covered details of each method and focused specifically on the equipment / methods available for use in class.

- Fracture modes: brittle, ductile; DBTT in steel, embrittlement, etc. Numerous pictures were presented to illustrate the appearances of these different failures

- Fatigue, examples and theory of what is occurring during fatigue and why it is a critical failure mechanism. Numerous case studies were presented

- Corrosion: types of corrosion, SCC, prevention methods, material selection

- Wear: modes (abrasive, adhesive, etc.), prevention and identification

- Case Studies of different failures

In general lectures did not spill over into lab time, which limited the amount of material covered.

Now fast-forward to $2004 \ldots$ 


\section{Winter 2004}

The mode of the course stayed the same with 2 laboratories and one lecture per week.

Significant structure was added to the lab portion and evolved over several years. Table 2 is an outline of the most recent course offering and is discussed in detail.

\begin{tabular}{|c|c|c|}
\hline Week & Lecture Topic & Lab Activity \\
\hline \hline 1 & Introduction / Failure Analysis & Lab Safety / Introduction, Failure Video \\
\hline 2 & Review of NDT & Calibration \& Materials Inspection Labs \\
\hline 3 & Review of NDT & Independent Work, Case Studies \\
\hline 4 & Fracture Modes & Independent Work, Case Studies \\
\hline 5 & Fracture Modes & Fatigue Activity/ Independent Work \\
\hline 6 & Failure design problem & Independent Work \\
\hline 7 & Fatigue & Independent Work \\
\hline 8 & Corrosion Failures & Independent Work \\
\hline 9 & Wear Failures & Independent Work / Presentations \\
\hline 10 & Liquid Metal Embrittlement & Presentations \\
\hline
\end{tabular}

Table 2. Winter 2004 Failure Analysis Course Outline

The significant change by 2004 was the increase in the diversity of lecture topics, the utilization of a textbook ("Understanding How Components Fail," by D.J. Wulpi), several structured lab experiments and design problems given in both lecture and lab. This was added to the base requirement of examining a failed component. Additionally, lecture would extend into lab time if necessary. Details of the curriculum are outlined below:

\section{Lecture}

The basic method of failure analysis is presented and discussed. The method is generic and can be applied to any type of failure or material. A focus on fracture and failed metallurgical samples is then presented. At this time the course still focuses on analysis of metals, though occasionally some polymer and composite failures were analyzed. A video shown in lab discussed several engineering failures and the methods employed to understand their cause.

Non-destructive testing (NDT) is discussed as the formal course is no longer offered. Using my course notes and modules developed at Iowa State University ${ }^{8}$, an abbreviated presentation is given and serves to illustrate how the different techniques are applied including their respective limitations and advantages. The objective is for students to select of the most appropriate technique despite their inability to actually perform the test.

Fracture modes are presented and illustrated through numerous examples. Students look at the component design and surmise why the failure occurred where it did. Discussion of how to improve the design and/or material and the ramifications of such changes follows. Numerous 
case studies are added so that students receive more exposure to how fractures are analyzed and prevented.

A failure design problem is presented where the students work in teams. The work is based on a product liability case for ATV handlebars done by the instructor. Additionally, other failure modes are discussed (wear, corrosion, etc.) and the interrelationship of failure modes is emphasized. The lecture has moved to more of a moderated group discussion where questions are posed and students are asked to respond and defend their opinions. The lectures are much more integrated and presented so students can see the connection of topics. This approach works as the students are seniors and the topics discussed build on courses already taken.

\section{Laboratory}

The major revision involved adding structured laboratories done in groups. These labs focused on failure analysis techniques, case studies and enhancing laboratory skills. The structured labs were designed to improve confidence, reduce anxiety and jump start the analysis process. For example, the first lab was inspection of materials. In this lab several engineering components were given to the students to inspect. The objective was to learn how to completely and accurately document a component. Simple failures were present but were not readily apparent, forcing students to look beyond the obvious.

The students were required to locate a failed component and encouraged to find something whose failure was not obvious. Then they were required to develop a project plan and defend it as being adequate but practical. Each week the students presented their progress and reported any challenges or problems encountered. The idea was to have peer discussion and to allow students to help and learn from one another. Students were given wide discretion and free time which they had to manage to ensure timely completion.

\section{Results \& Discussion}

The performance of the students was measured by the content of their technical report and ability to present their findings both orally and in writing. The results of modifying the failure analysis lab to include more design and more structure can only be measured qualitatively and subjectively. Since the class size is small $(<20)$ and offered only once per year, we must rely on student performance and feedback as metrics (albeit imprecise ones). The design component made the class more valuable for the following reasons:

- Students felt empowered as they chartered their own analysis course

- The analysis created more questions than answers

- As in life few things are as they first appear, i.e. results were unlike the predetermined labs done in previous courses

- The analysis process had definite characterization constraints that limited the depth and forced students to improvise

The design component added another dimension to the course. This is not to say that the original course was devoid of design, rather the new course took design from the background and pushed 
it to the forefront. The structured labs enabled the students to better design their analyses. This came directly from an improved skill set and an increase in confidence and familiarity of a variety of failed component case studies. The weekly discussions were of immense value as students could learn from each others past work experience and critique one another in a nonconfrontational setting. Additionally, the students were participating to some degree in everyone's project, making the class environment more like a big team as opposed to 20 individuals. Seeing the comradery and support was very rewarding and was reflected in the quality of work and overall moral of the class.

Based on the presentation of the new course the instructor learned several things:

- Students need to be pushed from their comfort zone if any type of meaningful design is to be achieved

- Not all students are going to be motivated nor wish to readily participate and I realize there are limitations to what I can do as an instructor

- There is a fine line between challenging and overwhelming which must be observed and monitored

Evidence of improvement was based on two metrics: quality of analysis and presentations and the anxiety student's felt during the quarter. These are both difficult to measure quantitatively given the low volume of students ( 20 /year) and the subjective nature of anxiety and performance. Anecdotal evidence was gathered in the form of class surveys (written and oral) during the course. Consistently students felt better prepared and confident in their failure design project than in past years. The evidence was in their comments regarding the structured failure labs performed earlier in the quarter. Example comments include: "I felt that looking at numerous failure mode enabled me to better understand the overall failure analysis process... and to design a process for examining my component" or "I wasn't sure what to expect coming into the class but after the $3^{\text {rd }}$ week I felt I had a strong understanding of what Failure analysis was about." Comments in past years often included criticism of feeling "set adrift" in their study. This was troubling given that these were seniors near graduation and this class closely mimicked the level of responsibility expected of them in industry. Nonetheless, the structured labs were deemed necessary to improve the student's learning and confidence, which ultimately will help them in their careers.

\section{Conclusions \& Future Work}

The design emphasis in this course enhanced the level of performance. The evaluation comments given by students support the observations presented. One area of improvement may be to have team projects covering several types of failures or short analyses of several failed components. This approach would reduce the design component but increase the exposure of failed parts. Students were divided on their opinion of lab and lecture time. Some felt more lecture was needed, while others wanted to keep the existing mode. This is being addressed by lecturing more in lab.

This failure analysis course is work in progress. The current offering (Winter 2005) adds one two more structured labs looking at several past student failure projects. These are done in 
groups to facilitate team work. Additionally, case studies are presented in each lab period. In essence the workload has increased and students have less unstructured lab time. This has an added benefit of forcing students to be more focused and efficient.

\section{Bibliography}

\footnotetext{
${ }^{1}$ Moll, A.J.et al., "What do you do with a B.S. in Materials Science and Engineering?" Journal of Materials Education, Vol. 24, No. 2-4, 2002. pp. 15-17.

${ }^{2}$ Taylor, J.B., et al., "An Integrated First Year Curriculum in Industrial \& Systems Engineering," Proceedings of the ASEE Annual Conference, Salt Lake City. UT. 2004

${ }^{3}$ Braatz, R.D., et al., "A Holistic Approach to Chemical Process Design and Development," Proceedings of the ASEE Annual Conference, Salt Lake City. UT. 2004

${ }^{4}$ Gani, R., "Chemical Product Design: Challenges \& Opportunities, " Computers \& Chemical Engineering, 28, 2004, pp. 2441-2457.

${ }^{5}$ Roylance, D., "An Undergraduate Capstone Subject in Design and Processing," Journal of Materials Education, Vol. 24, No. 1-3, 2002. pp. 231- 235.

${ }^{6}$ Fujiwara, M., et al. "A Holistic Approach to Materials Process Design," Journal of Materials Education, Vol. 24, No. 1-3, 2002. pp 65-71.

${ }^{7}$ Wulpi, D.J., Understanding How Components Fail, $2^{\text {nd }}$ Ed., ASM International, 2002, pp.1-6.

${ }^{8}$ http://www.ndt-ed.org
}

\section{Biography}

DAVID V. NIEBUHR is an Assistant Professor of Materials Engineering at California Polytechnic State University, SLO. He earned his Ph.D. in Materials Science \& Engineering in 1997 from the Oregon Graduate Institute of Science \& Technology and his B.S. in Materials Engineering from Cal Poly, SLO in 1993. His research interests included Tribology, Failure Analysis and solutions to materials degradation. 